\title{
Get the balance right
}

\author{
John M. Darlow AND David I. StOtT
}

Department of Immunology, Division of Infection, Inflammation and Immunity, University of Glasgow, Western Infirmary, Glasgow GI I 6NT, UK. (john.m.darlow@clinmed.gla.ac.uk)

Although it is important to preserve patient confidentiality, restrictions on publicly available data should be balanced with access to information so that legitimate research can proceed and prevent erroneous conclusions from being drawn.

We have recently made an observation concerning a DNA sequence from a tumor cell line that can only have two interpretations: either the cell line is not what it is supposed to be-in which case any research based on it may be invalidated - or a cherished assumption in immunology - that the identity of V(D)J junctional sequences from rearranged genes can be taken as proof of cell clonality - is overturned.

Each V(D)J recombination of immunoglobulin gene segments is thought to be unique. The identity of junctions has long been used as a marker of clonality during the progression of lymphoproliferative diseases ${ }^{1}$; it is also used in research on the $\mathrm{B}$ cell response and is now taken so much for granted that it is often not even stated ${ }^{2}$.

Ten years ago a set of three slightly different but extremely similar immunoglobulin heavy chain gene sequences were published that were said to come from transformed peripheral blood lymphocyte lines from different individuals ${ }^{3}$. The cell lines had been generated in the same laboratory $\mathrm{y}^{4,5}$ and the authors ${ }^{3}$ made several observations that satisfied them that the results were neither due to contamination of the DNA nor of the cell lines, but doubt may have remained because these findings were never followed up.

To establish whether similar V(D)J junctions could arise independently, we searched and found a sequence so similar that it would normally be assumed to be clonally related to the other three. The new sequence (BQ049789) was added to the EMBL database this year; it comes from the NIH Mammalian Gene Collection and is part of a cDNA library (NIH_MGC_85) said to be from a lymphoma cell line. NIH is unable to tell us the laboratory that generated the cell line or even the type of lymphoma because of legal advice regarding patient confidentiality.

It is very important to trace the source of this cell line in order to establish whether the new sequence is related to the first three. If the origins of cell lines are withheld this could hinder research in many areas. On the other hand, publication of the source of biological material should not breach patient confidentiality. We believe that new procedures should be put in place that preserve patient confidentiality without obstructing research.

I. Gulley, M. L., Dent, G.A. \& Ross, D.W. Cancer 69, 1600-1606 (1992)

2. Kim, H.-J. \& Berek, C. Arthritis Res. 2, |26-13| (2000)

3. Brokaw, J. L., Wetzel, S. M. \& Pollok, B. A. Int. Immunol. 4, 197-206 (1992).

4. Hendershot, L. \& Levitt, D.J. Exp. Med. 156, 1622-1634 (1982). 5. Hendershot, L. \& Levitt, D. J. Immunol., I32, 502-509 (1984). 